\title{
Photophysics of BODIPY Dyes as Readily-Designable Photosensitisers in Light-Driven Proton Reduction
}

\author{
Laura Dura ${ }^{1,+}$, Maria Wächtler ${ }^{2}$, Stephan Kupfer ${ }^{3}$, Joachim Kübel ${ }^{2,3, \ddagger}$, Johannes Ahrens ${ }^{4}$, \\ Sebastian Höfler ${ }^{4}$, Martin Bröring ${ }^{4}$, Benjamin Dietzek ${ }^{2,3, *}$ and Torsten Beweries ${ }^{1, *}$ \\ 1 Leibniz-Institut für Katalyse e.V. an der Universität Rostock, Albert-Einstein-Str. 29a, \\ 18057 Rostock, Germany; ldura@iciq.es \\ 2 Leibniz-Institut für Photonische Technologien e.V. Jena, Albert-Einstein-Straße 9, 07745 Jena, Germany; \\ maria.waechtler@leibniz-ipht.de (M.W.); joachim.kuebel@uni-jena.de (J.K.) \\ 3 Friedrich-Schiller-Universität Jena, Institut für Physikalische Chemie und, Helmholtzweg 4, \\ 07743 Jena, Germany; stephan.kupfer@uni-jena.de \\ 4 Institut für Anorganische und Analytische Chemie, TU Braunschweig, Hagenring 30, \\ 38106 Braunschweig, Germany; johannes.ahrens1@gmx.de (J.A.); sebastian-hoefler@t-online.de (S.H.); \\ m.broering@tu-braunschweig.de (M.B.) \\ * Correspondence: benjamin.dietzek@leibniz-ipht.de (B.D.); torsten.beweries@catalysis.de (T.B.); \\ Tel.: +49-3641-9-48360 (B.D.); +49-381-1281104 (T.B.) \\ † Current address: Institut Catatà d'Investigació Química, Avinguda dels Països Catalans 16, \\ 43007 Tarragona, Spain \\ $\ddagger$ Current address: Department of Chemistry and Molecular Biology, University of Gothenburg, \\ 40530 Gothenburg, Sweden
}

Academic Editor: Matthias Bauer

Received: 27 February 2017; Accepted: 29 March 2017; Published: 5 April 2017

\begin{abstract}
A series of boron dipyrromethene (BODIPY) dyes was tested as photosensitisers for light-driven hydrogen evolution in combination with the complex $\left[\mathrm{Pd}\left(\mathrm{PPh}_{3}\right) \mathrm{Cl}_{2}\right]_{2}$ as a source for catalytically-active Pd nanoparticles and triethylamine as a sacrificial electron donor. In line with earlier reports, halogenated dyes showed significantly higher hydrogen production activity. All BODIPYs were fully characterised using stationary absorption and emission spectroscopy. Time-resolved spectroscopic investigations on meso-mesityl substituted compounds revealed that reduction of the photo-excited BODIPY by the sacrificial agent occurs from an excited singlet state, while, in halogenated species, long-lived triplet states are present, determining electron transfer processes from the sacrificial agent. Quantum chemical calculations performed at the time-dependent density functional level of theory indicate that the differences in the photocatalytic performance of the present series of dyes can be correlated to the varying efficiency of intersystem crossing in non-halogenated and halogenated species and not to alterations in the energy levels introduced upon substitution.
\end{abstract}

Keywords: BODIPY; hydrogen; photochemistry; photophysics; quantum chemical simulations

\section{Introduction}

Light-driven production of hydrogen from aqueous media using homogeneous or heterogeneous multicomponent catalyst systems is regarded, nowadays, as a promising way to generate hydrogen as an alternative energy carrier or as a chemical feedstock. A plethora of highly active systems based on transition metals containing photosensitizers and water reduction catalysts are known and their photochemical and photophysical behaviour was thoroughly studied [1-3]. Recent developments include the implementation of non-noble metal components, or even metal-free compounds into these systems and several groups described the use of classical organic dyes, such as Fluorescein, 
porphyrins, or Eosin Y, as photosensitizer species [4-11]. Moreover, in recent years, BODIPY (boron dipyrromethene; IUPAC name: 4,4-difluoro-4-bora-3a,4a-diaza-s-indacene) dyes have also attracted considerable attention as light-harvesting units in inter- [12] and intramolecular [13-17] photocatalyst systems for light-driven proton reduction. In a study of dye-sensitised $\mathrm{TiO}_{2} / \mathrm{Pt}$ systems, Eisenberg and McCamant showed that incorporation of heavy atoms such as bromine or iodine at the 2,6 position of the BODIPY results in a pronounced coupling between singlet and triplet states that greatly decreases fluorescence quantum yield and fluorescence lifetime compared to the parent halogen-free compound and results in a more active photosensitizer [12]. This suggests the necessity of a strong intersystem crossing (ISC) to form a long-lived, high-yield triplet excited state for efficient photocatalysis. Further evidence for the important role of a triplet excited state was reported by the groups of Weare and Luo for intermolecular [16], as well as intramolecular [13,15-17] BODIPY-cobaloxime systems. More recently, Eisenberg et al. have used a combination of strongly light-absorbing BODIPYs and platinum diamine dithiolate charge transfer chromophores for sensitizing $\mathrm{TiO}_{2}$ in light-driven reduction of aqueous protons $[18,19]$. A survey of the combined influence of BODIPY halogenation and introduction of sterically-demanding aryl groups on photocatalytic hydrogen production activity was presented by the same authors, showing the presence of a pronounced heavy atom effect as well as an enhanced dye stability with an increase in steric demand at the meso position [20].

In our group, we have described a catalyst system constituted from a series of BODIPYs (1-6) as a photosensitizer (PS), triethylamine (TEA) as a sacrificial electron donor, and $\left[\mathrm{Pd}\left(\mathrm{PPh}_{3}\right) \mathrm{Cl}_{2}\right]_{2}$ as a precursor for catalytically-active Pd nanoparticles in THF/water (Figure 1) [21]. As for the reaction mechanism, the commonly-accepted reductive pathway of photoexcitation of the dye, followed by quenching by the electron donor and electron transfer to the reduction catalyst is discussed. The alkynyl substituted compounds $\mathbf{7}$ and $\mathbf{8}$ were not reported as PS before and were included in the present study as the interaction of the Pd nanoparticles with the acetylide group might result in the in situ formation of a homogeneous/heterogeneous dyad-like system by interaction of the Pd site with the $\pi$ system of the BODIPY side chain.

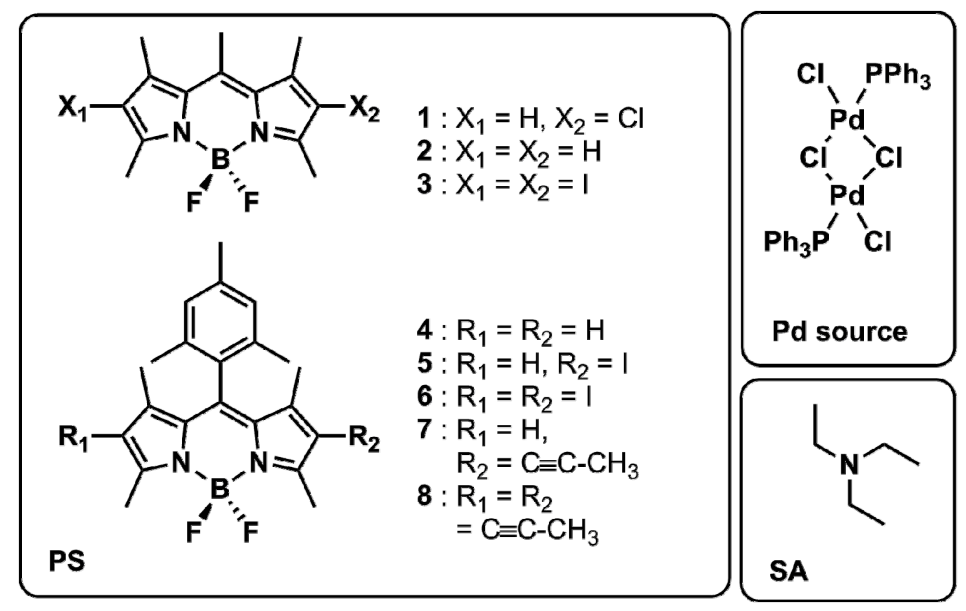

Figure 1. Components of the multicomponent catalyst systems presented.

By modification of the BODIPY substitution pattern, the chemical stability, as well as the activity of the photocatalytic system was improved significantly. The main reasons for this were found to be a pronounced internal heavy atom effect due to iodine substitution as well as the introduction of sterically demanding mesityl groups in the meso position, thus preventing hydrogenation and degradation of the dye. This very convenient synthetic modification by classical organic transformations has direct consequences for the photochemical and photophysical properties of the respective BODIPY [22], making this class of compounds very attractive for further applications. 
In this contribution, we extend these studies by looking further into the photophysics and photochemistry of these organic dyes. By combination of catalytic results with photophysical investigations and state-of-the-art quantum chemical calculation carried out at the MS-CASPT2 [23,24] (multi-state second-order perturbation correction on a state average complete active space self-consistent field reference wavefunction), as well as at the (time-dependent) density functional level of theory ((TD)DFT), we attempt to develop a reaction mechanism.

\section{Results and Discussion}

\subsection{Photophysical Characterisation of the BODIPY Dyes}

The absorption and emission spectra of BODIPY dyes 1-8 show that variation of $\beta$-substituents strongly influences the electronic properties of these dyes. Compared to the parent compound dye 4 , iodine, as well as alkynyl substitution, results in a bathochromic shift of both main absorption and emission features (Figures S3 and S4). Furthermore, the emission quantum yield varied from a maximum of $7 \%$ for the iodine substituted dyes 3, 5, and 6 to a maximum of $97 \%$ for compound 2 (Table 1). These values are in line with previous reports of heavy atom containing BODIPYs showing low emission quantum yields due to increased ISC from the initially excited ${ }^{1} \pi \pi^{*}$ state [20]. Additionally, molar absorptivities were slightly higher for mesityl-substituted BODIPYs 4 and 6 compared to methyl analogs 2 and 3, respectively. Stationary emission quenching experiments using the sacrificial agent TEA as a quencher displayed Stern-Volmer behaviour for all dyes with Stern-Volmer constants ranging from $23.0 \mathrm{~L} / \mathrm{mol}$ for $\mathbf{1}$ to $1.05 \mathrm{~L} / \mathrm{mol}$ for $\mathbf{6}$ (Table 1). Lower Stern-Volmer constants were found for dyes with iodine as well as alkynyl substitution in $\beta$-position (Figures S6-S8), which is an indication for a reduced efficiency of the quenching process.

Table 1. Selected results from stationary optical spectroscopy. All measurements were conducted on $10^{-5} \mathrm{M}$ solutions of the dyes in THF $\left(\lambda_{\mathrm{abs}}\right.$ : wavelength of the maximum absorption, $\varepsilon$ : absorption coefficient at the wavelength of maximum absorption, $\lambda_{\mathrm{em}}$ : wavelength of the maximum emission, $K_{\mathrm{SV}}$ : Stern-Volmer constant from TEA quenching experiments, $k_{\mathrm{q}}=K_{\mathrm{SV}} / \tau_{\mathrm{em}}$ ).

\begin{tabular}{|c|c|c|c|c|c|c|}
\hline PS & $\begin{array}{c}\lambda_{\mathrm{abs}}{ }^{a} \\
(\mathrm{~nm})\end{array}$ & $E^{\mathrm{b}}(\mathrm{L} / \mathrm{mol} \cdot \mathrm{cm})$ & $\lambda_{\mathrm{em}}^{\mathrm{c}}(\mathrm{nm})$ & $\Phi_{e m}^{d}(\%)$ & $K_{\mathrm{SV}}(\mathrm{L} / \mathrm{mol})$ & $k_{\mathrm{q}}\left(10^{9} \mathrm{~L} / \mathrm{mol} \cdot \mathrm{s}\right)$ \\
\hline 1 & 506 & 80,600 & 537 & 94 & $23.0 \pm 0.9$ & $3.8^{\mathrm{e}}$ \\
\hline 2 & 496 & 62,700 & 526 & 97 & $6.46 \pm 0.1$ & $1.2^{\mathrm{e}}$ \\
\hline 3 & 526 & 77,000 & 559 & 7 & $1.43 \pm 0.1$ & $>1.4^{\mathrm{f}}$ \\
\hline 4 & 502 & 84,400 & 523 & 91 & $14.2 \pm 0.4$ & $3.1 \pm 0.4$ \\
\hline 5 & 516 & 85,500 & 543 & 3 & $1.10 \pm 0.1$ & $3.4 \pm 0.7$ \\
\hline 6 & 534 & 89,700 & 565 & 1 & $1.05 \pm 0.03$ & $5.5 \pm 0.7$ \\
\hline 7 & 530 & 62,500 & 555 & 70 & $5.04 \pm 0.2$ & $1.0 \pm 0.2$ \\
\hline 8 & 549 & 55,000 & 579 & 85 & $2.93 \pm 0.3$ & $0.6 \pm 0.1$ \\
\hline
\end{tabular}

Time-dependent emission measurements were performed for all mesityl-substituted dyes 4-8 (Table 2). The results reveal increasing emission lifetimes with increasing emission quantum yield up to a maximum of about $5 \mathrm{~ns}$. With iodine substitution in $\beta$-position the emission lifetimes decreases to 320 ps for 5 and 190 ps for $\mathbf{6}$. This effect was observed before by other groups for structurally-similar meso-phenyl BODIPYs and can be explained by fast intersystem crossing (ISC) and the population of non-emitting long-lived triplet states $[12,20,27,28]$. To detect the presence and identify non-emitting long-living states transient absorption spectroscopy with a time window of up to $1 \mathrm{~ms}$ was performed. The iodine substituted dyes $\mathbf{5}$ and $\mathbf{6}$ showed population of a long-living state which decays biexponentially with lifetimes of 28 and $120 \mu$ s for (5) and 37 and $150 \mu$ s for (6) in an oxygen-free solution. The transient absorption spectra (Figure 2) show a negative ground state bleach feature around the absorption band position in the ground state absorption spectra, a strong 
positive excited state absorption band around $440 \mathrm{~nm}$, and a weaker broad positive excited state absorption feature at wavelengths longer than $550 \mathrm{~nm}$, which is in good agreement with spectral features of triplet states reported for similar BODIPY dyes [12,25]. Emission from the long-living triplet state was not observed in accordance with previous results that BODIPY dyes seldom show phosphorescence [29]. The population of triplet states in the iodine substituted species is due to enhanced ISC induced by the heavy atom effect of the iodine substituents. This coincides with a lack of long-lived states on the $\mu$ s timescale in ns transient absorption measurements for the unsubstituted dye 4 and the alkynyl substituted dyes 7 and 8 (Figures S10-S13). To complete the picture of the ISC processes in meso-mesityl iodine-substituted BODIPYs the time constants for the formation of the long-lived triplet state in 5 and $\mathbf{6}$ were determined to be 354 and 240 ps, respectively, by globally fitting of spectrally-resolved data from fs time-resolved transient absorption spectroscopy (see Supplementary Materials). This is in good agreement with the strongly reduced emission lifetimes and low emission quantum yields found for both compounds.

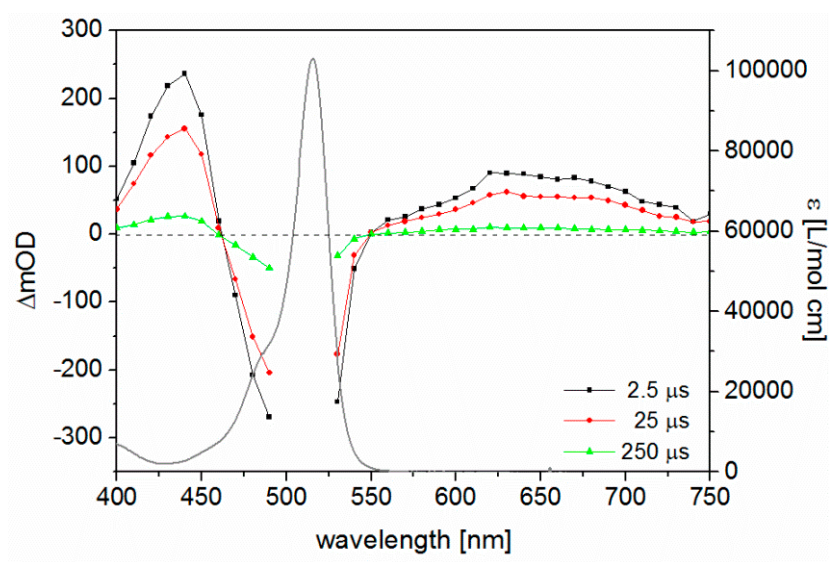

Figure 2. Transient absorption spectra of 5 in THF at chosen delay times (black, red and green) upon excitation with pump pulses centred at $515 \mathrm{~nm}$ and stationary absorption spectrum (grey).

Quenching experiments of the emitting singlet state with TEA and dyes 4, 5, and 7 showed that the fluorescence lifetimes of all three dyes decreased when TEA was added to the sample (Table S1, Figure S9). Stern-Volmer plots showed slopes of $11.26 \mathrm{~L} / \mathrm{mol}$ (4), $1.12 \mathrm{~L} / \mathrm{mol}(5)$, and $5.11 \mathrm{~L} / \mathrm{mol}$ (7). Thus, shortening of emission lifetime and quenching emission intensity by TEA behave similarly, as is characteristic for dynamic quenching. The reduced Stern-Volmer constants for $\mathbf{5}$ and $\mathbf{6}$ can be rationalised with the short lifetime of the emitting singlet state because the electron transfer from the sacrificial agent cannot compete efficiently with the deactivation of the emitting state by ISC. For 7 and 8 a reduced quenching rate constant, probably due to sterical constraints by the substituents, causes a decreased efficiency of the quenching process compared to 4.

Table 2. Selected results from time-dependent spectroscopy. All measurements were conducted in THF with optical densities as befits the used method ( $\tau_{\mathrm{em}}$ : emission lifetime, $K_{\mathrm{SV}}(\tau)$ : Stern-Volmer constant for emission life time quenching with TEA, $\tau_{\text {ex }}$ : emission lifetime of long-living excited state as obtained from transient absorption spectroscopy with a time window of up to $\left.1 \mathrm{~ms}, k_{\mathrm{q}}=K_{\mathrm{SV}}(\tau) / \tau_{\mathrm{em}}\right)$.

\begin{tabular}{|c|c|c|c|c|c|}
\hline PS & $\tau_{\mathrm{em}}{ }^{\mathrm{a}}$ (ns) & $K_{\mathrm{SV}}(\tau)(\mathrm{L} / \mathrm{mol})$ & $\tau_{\mathrm{ex} 1} \mathrm{~b}(\mu \mathrm{s})$ & $\tau_{\mathrm{ex} 2} \mathrm{~b}(\mu \mathrm{s})$ & $k_{\mathrm{q}}\left(10^{9} \mathrm{~L} / \mathrm{mol} \cdot \mathrm{s}\right)$ \\
\hline 4 & 4.62 & $11.26 \pm 0.28$ & $-d$ & $-d$ & $2.4 \pm 0.3$ \\
\hline 5 & 0.32 & $1.12 \pm 0.14$ & 28 & 120 & $3.5 \pm 0.9$ \\
\hline 6 & 0.19 & $-/-c$ & 37 & 150 & $-/-c$ \\
\hline 7 & 5.02 & $5.11 \pm 0.16$ & $-d$ & $-d$ & $1.0 \pm 0.1$ \\
\hline 8 & 4.79 & $-/-c$ & $-d$ & $-d$ & $-/-c$ \\
\hline
\end{tabular}

a $\pm 10 \%$; ${ }^{b} \pm 20 \%$, deoxygenated solution; ${ }^{c}$ The specified experiments were not performed for these dyes; ${ }^{\mathrm{d}}$ no long-living species observed. 
It should be noted that, for the triplet states at high concentrations, self-quenching via triplet-triplet annihilation can occur. This will decrease the observed lifetime of the triplet states. Assuming a diffusion controlled quenching process $\left(k_{\mathrm{TTA}}=1 \times 10^{-9} \mathrm{~L} / \mathrm{mol} \cdot \mathrm{s}\right)$ and a lifetime of the triplet states (without any additional quenching process) of $\tau_{\text {nat }}=10-100 \mu$ s the following observed lifetime for the triplet states with a concentration of excited molecules (BODIPY*) of $1 \mathrm{mM}$, which is an overestimation, as this would mean that all molecules in the sample are excited, can be calculated:

$$
\begin{gathered}
k_{o b s}=k_{n a t}+k_{T T A} \cdot c\left(\text { BODIPY }^{*}\right)=\left(1 \times 10^{4}\right) \mathrm{s}^{-1}+\left(1 \times 10^{9}\right) \mathrm{L} \cdot \mathrm{mol}^{-1} \cdot \mathrm{s}^{-1} \times\left(1 \times 10^{-3}\right) \mathrm{mol} \cdot \mathrm{L}^{-1}=1 \times 10^{6} \mathrm{~s}^{-1} \\
\tau_{o b s}=1 / k_{o b s}=1 \mu \mathrm{s}
\end{gathered}
$$

This value can be regarded as lower limit for the expected observable lifetime at this concentration. Compared to the singlet lifetimes of the BODIPY dyes, which are not forming triplets, which is in the range of several ns, this is significantly longer and, hence, efficient quenching via electron transfer can be expected. Especially at the concentrations of the sacrificial electron donor used in the catalysis experiments $(2900 \mathrm{mmol} / \mathrm{L})$, the quenching via electron transfer is expected to be much faster than the decay of the triplet states and no significant impact of the possible self-quenching on the hydrogen evolution is expected.

\subsection{Quantum Chemical Calculations}

In order to further understand the nature of the excited states populated upon photoexcitation of the BODIPY dyes, we performed quantum chemical calculations for selected compounds ( 2 and 4-8). Details with respect to the computational protocol are collected in the Experimental Section under quantum chemical calculations. The comparison of MS-CASPT2 and TDDFT results is given in Table S2, while the molecular orbitals involved in the leading TDDFT transitions are illustrated in Table S3. As an example, the UV-VIS absorption spectrum of compound 2 is depicted along with the simulated MS-CASPT2 and TDDFT spectra in Figure 3.

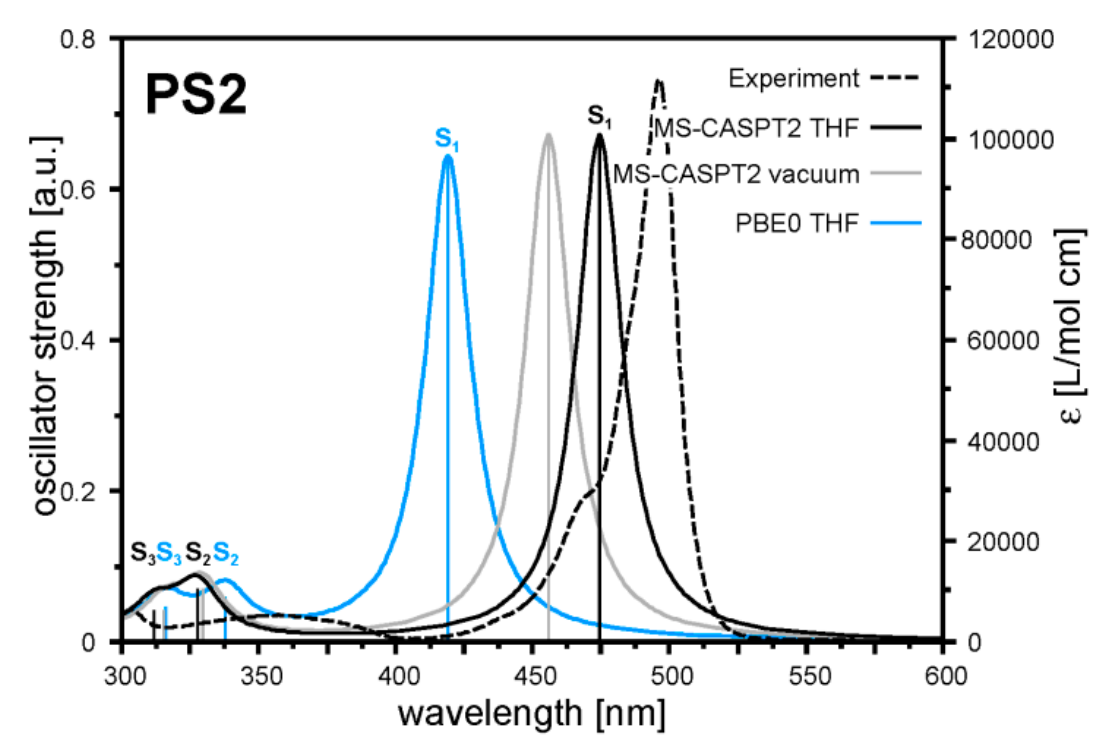

Figure 3. Experimental (black dashed line) and calculated UV-VIS absorption spectrum of 2 at MS-CASPT2 (solvent corrected: solid black, gas phase: solid grey) and PBE0 levels of theory (solvent-corrected: solid blue).

Typically, for BODIPY dyes, TDDFT overestimates the excitation energy of the bright absorption band [30-33] (measured in THF) in the visible region centred at $497 \mathrm{~nm}(2.49 \mathrm{eV})$, assigned to the excitation into the $S_{1}$ state at $419 \mathrm{~nm}(2.96 \mathrm{eV})$, by approximately $0.5 \mathrm{eV}$, similar hypsochromic shifts 
were observed for the UV bands (see states $\mathrm{S}_{2}-\mathrm{S}_{4}$ in Table S2). This overestimation of the excitation energies is reasoned by the lack of TDDFT to address the multi-configurational character and by the inability to describe double excitations (DE). MS-CASPT2/SA-CASSCF predicts partially-pronounced multi-configurational character for the excited singlet states, while $S_{2}, S_{3}$, and $S_{4}$ also hold contributions of doubly-excited configurations. Thus, the $\mathrm{S}_{1}$ state (MS-CASPT2) is approximately $0.3 \mathrm{eV}$ lower than in the TDDFT scheme, while a further solvent stabilisation (predicted at the TDDFT level of theory) of $0.1 \mathrm{eV}$ leads to a MS-CASPT2 energy of the $\mathrm{S}_{1}$ state of $\sim 2.62 \mathrm{eV}$, which is in good agreement with the experimental value of $2.49 \mathrm{eV}$. Less multi-configurational character is found for the low-lying triplet states. However, here a reversed trend with respect to the TDDFT excitation energies is observed; TDDFT predicts the excitation energy approximately $0.4 \mathrm{eV}$ lower than the corresponding triplet state using the MS-CASPT2 methodology. In general, these computational results are in agreement with [33].

Since the computational demand for the dyes 4-8 increases substantially, we restrict the computational level used to describe the properties of these dyes to affordable TDDFT simulations. The absorption spectra of these dyes are given by the singlet excited states in the $\mathrm{S}_{0}$ geometry, while the transient absorption spectra, or rather the excited state absorption contributions of the triplet states to the transient absorption spectra, is modelled by the spin-allowed bright triplet-triplet excitation within the $\mathrm{T}_{1}$ structure (see computational protocol in the sub-section on quantum chemical calculations in the Experimental section). The UV-VIS and the triplet absorption spectra are depicted in Figure S17, while the properties of the bright singlet and triplet excited states are summarised in Tables S5 and S6.

To elucidate the origin of the long-lived excited state observed for $\mathbf{5}$ and $\mathbf{6}$, and their multiplicity, the experimental transient spectra are compared to the quantum chemical calculations of the excited state absorption spectra. The shape of the simulated spectrum agrees well with the experimental observations (Figure S17b), and allows an assignment of the broad arising absorption feature between 750 and $550 \mathrm{~nm}$ to excitations into the weakly-absorbing excited triplet states $T_{5}$ and $T_{8}$ at 622 and $605 \mathrm{~nm}$, respectively. Furthermore, the bright absorption feature at approximately $440 \mathrm{~nm}$ (Figure 2) is correlated with an excited state absorption into the $\mathrm{T}_{10}$ state at $378 \mathrm{~nm}$. Notably, excitation into $\mathrm{T}_{5}$ and $\mathrm{T}_{10}$ leads to a pronounced charge-separation due to the charge transfer character of the underlying electronic transitions from the central boron fragment to the mesityl moiety, while the $T_{6}$ state is of a locally-excited character (boron fragment).

In addition, TDDFT single point calculations were performed within the optimised equilibrium structures of the singlet ground state $\left(\mathrm{S}_{0}\right)$, the first bright singlet excited state $\left(\mathrm{S}_{1}\right.$, populated upon photoexcitation and subsequent vibronic cooling), and the triplet ground state ( $\mathrm{T}_{1}$, populated upon ISC and excited state relaxation in the triplet manifold). The energies of the respective singlet and triplet states of 4-8 within the $S_{0}, S_{1}$, and $T_{1}$ geometries are summarised in Table S4, while the MOs involved in the leading transitions are depicted in Table S5. From these data it is evident that the relative energetic positions of the low-lying singlet and triplet states along the proposed excited state's relaxation pathway is very similar for all five meso-mesityl substituted dyes. Therefore, the observed differences in the excited states' relaxation cascades, i.e., between $\mathbf{4}$ and $\mathbf{5}$ and $\mathbf{6}$, are attributed to the efficiency of the ISC and not to alterations in the energy levels introduced upon substitution. However, to investigate this phenomenon further spin-orbit couplings need to be calculated.

\subsection{Hydrogen Evolution Experiments on BODIPY Sensitised Multicomponent Catalyst Systems}

As established above BODIPY dyes provide promising possibilities to adjust crucial optical properties of photosensitisers in multicomponent catalyst systems as their photophysical characteristics are easily tunable using common synthetic approaches. Additionally, the long-term stability under reaction conditions can be addressed by the introduction of organic substituents at the BODIPY core unit. In a previous study, we have used meso-methyl substituted BODIPY dyes 1-3 in the above-described multicomponent catalyst system (Figure 4) [21]. 


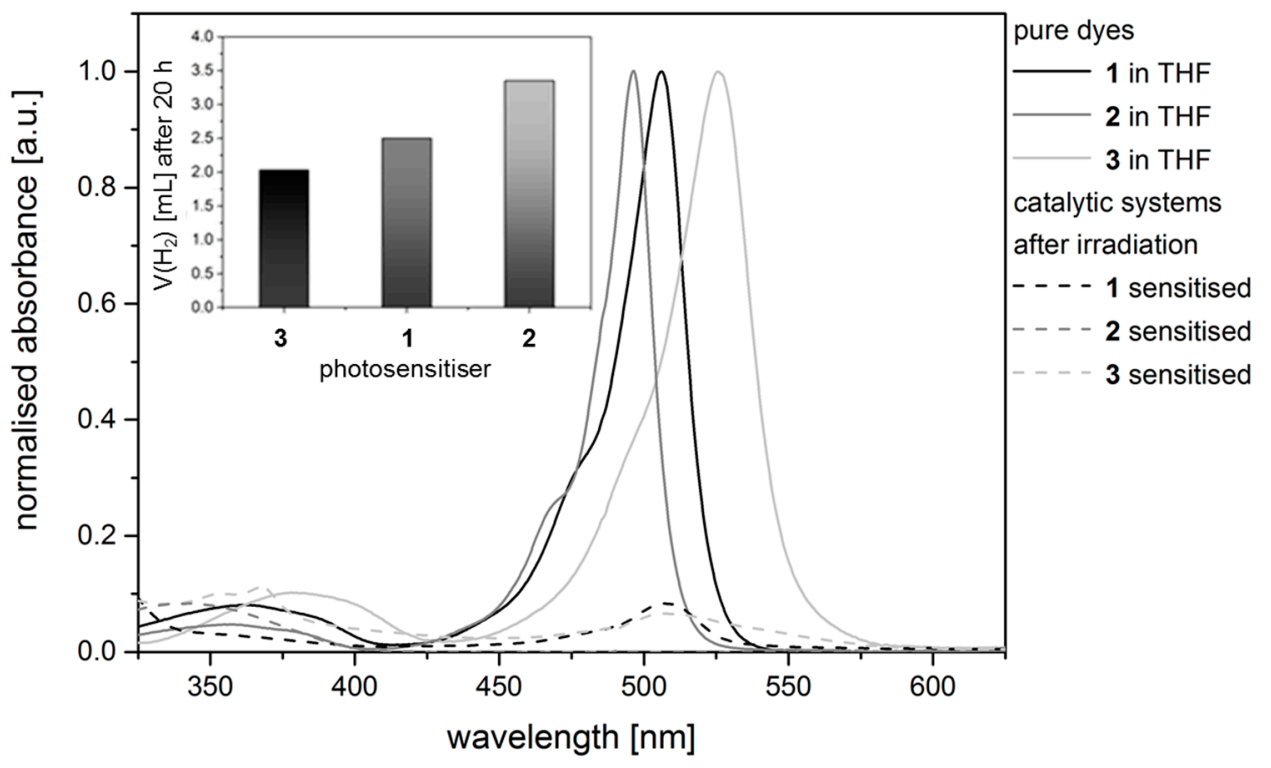

Figure 4. Absorption spectra of pure BODIPY dyes 1, 2, and 3 before (solid lines) and after (dashed lines) utilisation in a multicomponent catalyst system.

Unfortunately the multicomponent catalyst systems showed only moderate activities and ceased to be active after $20 \mathrm{~h}$ of irradiation. Analysis of the reaction mixture using optical spectroscopy and electrospray ionisation mass spectrometry (ESI-MS) indicated degradation of the BODIPY dye, thus causing the deactivation of the multicomponent catalyst systems. Indeed, the addition of fresh PS reactivated the systems that became inactive previously. Furthermore, ESI mass spectra measured after the reaction showed fragments corresponding to the presence of hydrogenated BODIPY dyes, thus pointing towards hydrogenation, instead of a photodegradation reaction, as the reason for deactivation of the meso-methyl substituted BODIPY dyes.

Since the meso position is known to be most sensitive to hydrogenation reactions [34], this position was protected by a sterically-demanding mesityl group. The resulting BODIPY dye 4 was not only highly active as a photosensitizer in light-driven proton reduction but also showed long-term stability exceeding $20 \mathrm{~h}$. A beneficial electronic effect of the mesityl group, stabilising the radical anion $\mathbf{4}^{-}$ that could, in principle, form upon reaction with the sacrificial reductant TEA can be excluded since, in compounds of this type, the aromatic group is in an orthogonal orientation with respect to the BODIPY core [35]. Additionally, in quantum chemical calculations, no substantial singlet transitions from the boron to the mesityl fragment are observed due to the lack of overlap of $\pi$ systems. However, TDDFT calculations revealed low-lying charge-separated excited triplet states (e.g., $\mathrm{T}_{8}$ for compound 4 , see Supplementary Materials for details) that may be populated upon ISC. The presence of such charge-separated states points to the ability of the mesityl group to stabilise an additional excess charge like in case of the reactive $4^{-}{ }^{-}$species. Thus, compound 4 presented an excellent basis for the modification of photophysical properties. Only by modification of the $\beta$-substituents of 4 , an ensemble of overall five meso-mesityl substituted BODIPY dyes (dyes 5-8, Figure 5) was designed which each could be expected to show excellent long term stability under reaction conditions. 


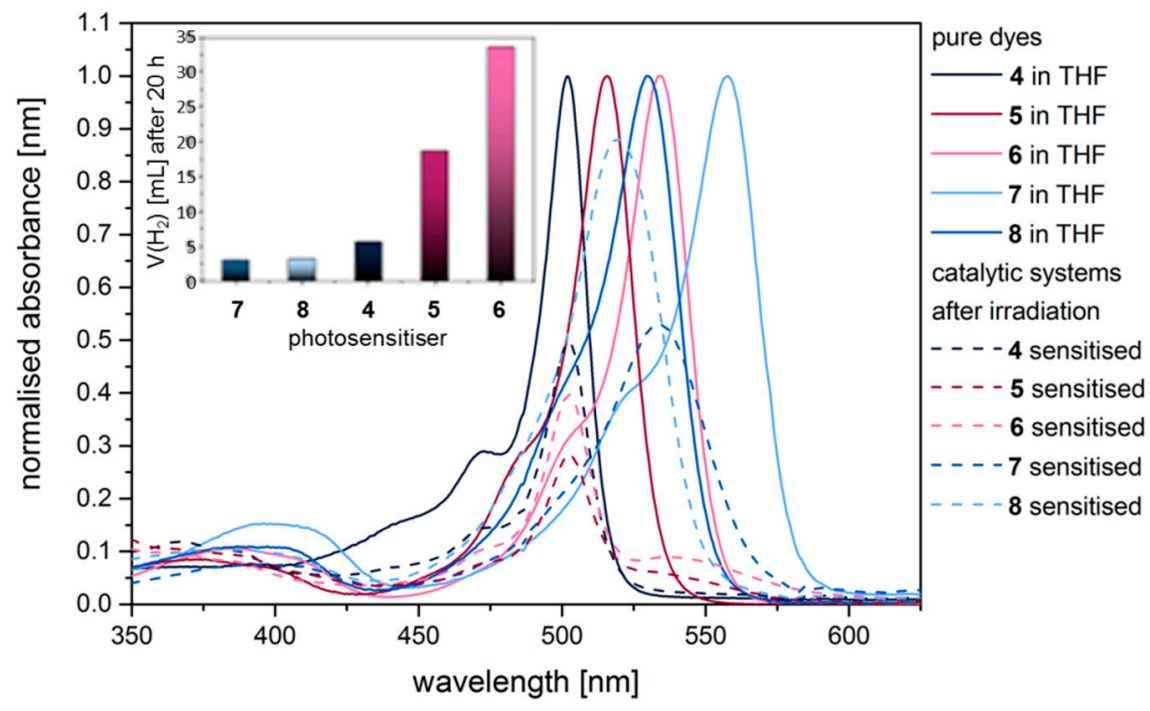

Figure 5. Absorption spectra of pure BODIPY dyes 4-8 before (solid line) and after (dashed line) irradiation in a multicomponent catalyst system for 16-200 h.

All meso-mesityl-substituted BODIPY dyes (4-8) proved to be catalytically-active PS in the presented multicomponent systems using in situ-generated $\mathrm{Pd}$ nanoparticles as the reduction catalyst and TEA as the sacrificial agent in a THF $/ \mathrm{H}_{2} \mathrm{O}$ (11:3) mixture (Figure S1). As envisioned, great differences in long-term stability, as well as performance, were observed with outstanding results for the heavy atom substituted dyes: The doubly iodine-substituted dye 6 produced an overall amount of $35 \mathrm{~mL}$ of hydrogen and was active for up to $250 \mathrm{~h}$, thus outperforming the well-known noble-metal containing PS [Ru(bpy $\left.)_{3}\right]^{2+}$ under similar reaction conditions [21]. Unfortunately optical spectroscopy indicated that all $\beta$-substituted dyes were not as stable as $\mathbf{4}$ under reaction conditions (Figure S5). In absorption, as well as emission spectra, the main signal of pure dyes displays a bathochromic shift with substitution of the $\beta$-position (Table 1). Analysis of the absorption spectra after irradiation of catalytic systems sensitised by 5 or $\mathbf{6}$ (Figure 5, dashed line) shows an intense signal at around $500 \mathrm{~nm}$ after $20 \mathrm{~h}$ of irradiation which coincides with the main absorption of dye 4 . This indicates a cleavage of carbon-iodine bonds and thus degradation of 5 and $\mathbf{6}$ to the unsubstituted dye $\mathbf{4}$ as was observed before for other halogenated organic photosensitisers [9]. ESI mass spectrometry supports this explanation. However, this does not result in deactivation of the multicomponent system in the first place, since all three dyes are active photosensitisers. Thus, excellent long-term activities of systems sensitised by $\mathbf{5}$ or 6 were obtained.

Likewise, compounds containing alkynyl side groups were not stable under reaction conditions. Absorption spectra, as well as stationary emission spectra measured after irradiation, show a slight hypsochromic shift of the main absorption from $530 \mathrm{~nm}(7)$ and $549 \mathrm{~nm}(8)$ to $520 \mathrm{~nm}$ and $540 \mathrm{~nm}$, respectively. Nevertheless, in ESI-MS no cleavage of the side chains could be verified. Instead, MS analysis after reaction gives evidence for the hydrogenation of the carbon-carbon triple bond, which possibly leads to deactivation of the catalytic system. Hence, no beneficial effect of interaction of Pd centres with the unsaturated side chain could be observed.

Only 4 proved unaffected by photodegradation after $20 \mathrm{~h}$ of irradiation, however, after $43 \mathrm{~h}$ of irradiation only $50 \%$ of the original amount of 4 remained as is shown in Figure 5. MS analysis of the solution to identify the fate of the dye 4 in long term experiments did not allow for an identification of possible decomposition products. Absorption spectra measured during a hydrogen evolution experiment proved that after $2 \mathrm{~h}$ of irradiation all dyes remained chemically stable. Subsequently, degradation of the meso-methyl substituted dyes is observed leading to almost complete decay of $\mathbf{1}, \mathbf{2}$, and 3. Furthermore, after 5-7 h of photolysis cleavage of the C-I bonds of the iodine-substituted dyes 5 and 6 became evident, but at least $70 \%$ of the original amount of dye remained. After an irradiation 
time of 16-45 h, which depending on the dye corresponds to the active phase of the catalyst system, absorption spectra of all dyes showed distinct hypochromic (all dyes) and in some cases hypsochromic shifts $(1,5,6,7,8)$.

Further investigations concerning the water reduction catalyst indicated the degradation of the Pd complex to $\mathrm{Pd}^{0}$ nanoparticles which act as catalysts on a long term basis. Transmission electron microscopy (TEM) after reaction showed agglomerations of 2-5 nm sized nanoparticles of $\mathrm{Pd}$, which in some cases even formed precipitates [21]. Since only the addition of fresh PS reactivated the multicomponent systems, these in situ-formed nanoparticles must be the active water reduction catalyst. Moreover, a clear difference between multicomponent catalyst systems with long-term activity and deactivating systems is evident from diagrams of $\mathrm{H}_{2}$ evolved per hour (Figure 6). The top diagram shows a deactivating system containing BODIPY 3 with steadily decreasing amounts of $\mathrm{H}_{2}$ evolved per hour, approaching a value of zero within $20 \mathrm{~h}$. In systems that are long-term stable and active, such as those containing dye 4 (Figure 6b), a constant significant amount of $\mathrm{H}_{2}$ is evolved per hour within $5 \mathrm{~h}<t<20 \mathrm{~h}$. However, the amount of $\mathrm{H}_{2}$ evolved during the first hour is at least twice as high as within the second hour.

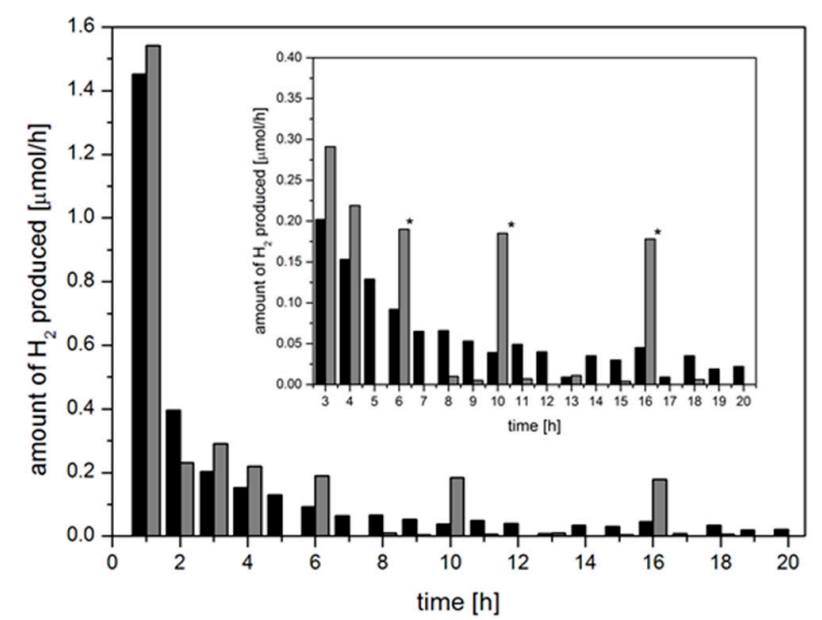

(a)

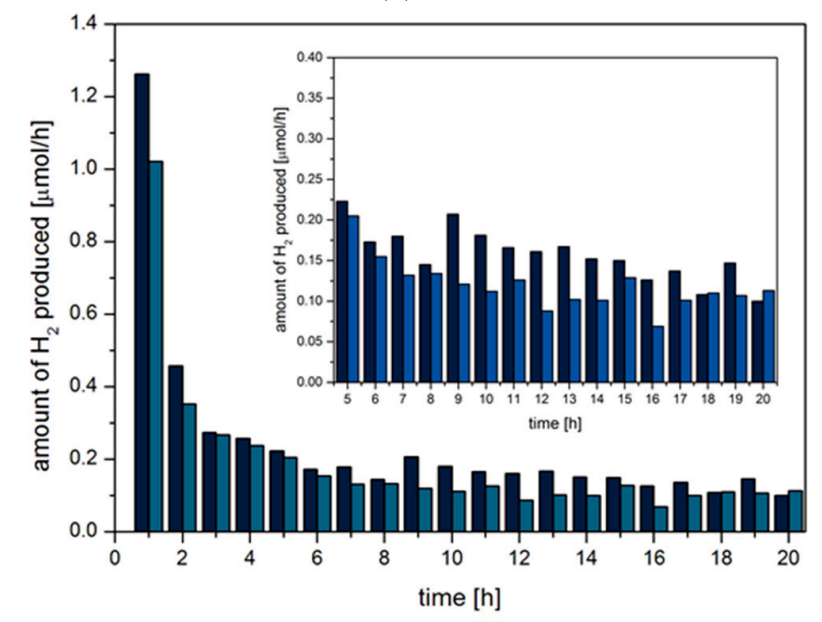

(b)

Figure 6. Amounts of hydrogen produced per hour within the first $20 \mathrm{~h}$ of irradiation using a multicomponent system containing the degrading dye 3 (a) and the stable dye $4(\mathbf{b})$. Two columns for each system show results from two independent experiments. The insets show an enlarged section of the graph illustrating the different behaviour of degrading and stable dyes. The asterisks mark outliers that originate from internal mistakes of the volume correction during measurements. 
This allows for two explanations of the fast deactivation of the system after the first hour:

(a) The $\mathrm{Pd}$ nanoparticle precursor $\left[\mathrm{PdCl}_{2}\left(\mathrm{PPh}_{3}\right)\right]_{2}$ serves as a highly active water reduction catalyst at the onset of irradiation, but degrades during the first hour to the less active Pd nanoparticles which were confirmed via transmission electron microscopy after reaction (Scheme 1a).

(b) $\left[\mathrm{PdCl}_{2}\left(\mathrm{PPh}_{3}\right)\right]_{2}$ is an inactive precursor and degrades to highly-active Pd nanoparticles within the first seconds of irradiation. During the first hour of irradiation performance of these nanoparticles slightly decreases due to aggregation (Ostwald ripening) or blocking of active centres by a component present in solution (Scheme 1b).

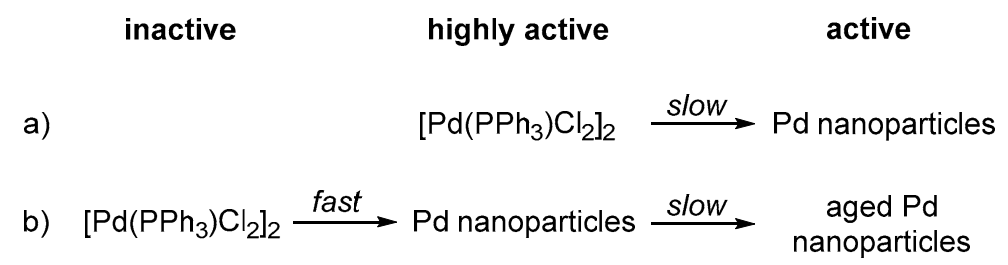

Scheme 1. Schematic representation of possible mechanisms for formation of the active catalyst during irradiation.

To test this hypothesis we performed an irradiation experiment with addition of elemental $\mathrm{Hg}$ to the multicomponent system consisting of dye 5, the molecular Pd complex, water, and TEA before starting the irradiation. We found that under the same reaction conditions the overall volume generated by photolysis of this mixture strongly differs in the presence and in the absence of $\mathrm{Hg}$ $(20 \mathrm{~mL}$ vs. $<2 \mathrm{~mL}$ ), suggesting that a catalytically inactive $\mathrm{Pd} / \mathrm{Hg}$ amalgam is formed directly at the onset of irradiation (Figure S2). In an earlier study [21], addition of $\mathrm{Hg}$ during photolysis resulted in a complete decay of hydrogen production activity, suggesting the formation of a catalytically inactive amalgam. In absorption spectra the signal of $\left[\mathrm{PdCl}_{2}\left(\mathrm{PPh}_{3}\right)\right]_{2}$ is overlaid by absorptions of the PS, thus preventing reaction monitoring by in situ absorption spectroscopy. Additionally, no resonances due to the molecular Pd complex could be observed by in situ ${ }^{31} \mathrm{P}-\mathrm{NMR}$ studies using a combination of 5, Pd precursor, TEA, and water. We, thus, believe that mechanism (b) is more likely. The constant activity of systems sensitised by $4-6$ between 5 and $20 \mathrm{~h}$ indicates the presence of a stable PS and reduction catalyst during this period [21].

\subsection{Correlation of Photophysical Properties and Performance of BODIPY Dyes}

Due to the previously-described results, the activities of the multicomponent catalyst systems at times $t<1 \mathrm{~h}$ are readily comparable. Furthermore 4-6 sensitised systems are comparable on a $5 \mathrm{~h}<t<$ $20 \mathrm{~h}$ time scale, too. Dyes 4,7 , and 8 are active photosensitisers despite not forming triplet states, as transient absorption spectroscopy revealed. The same behaviour can be expected from meso-methyl substituted dyes 1 and 2 which have similar fluorescence quantum yields as 4,7 , and 8 . This indicates a hitherto undescribed sensitisation pathway from the excited singlet state for dyes 1, 2, 4, 7, and 8 . Comparably long lifetimes of the BODIPY dye $S_{1}$ state (up to $5 \mathrm{~ns}$ in the case of the dyes presented) make this assumption even more probable. In accordance with this interpretation all dyes showed clear fluorescence quenching upon addition of TEA and an enhanced performance within the first hour of irradiation with increasing Stern-Volmer constants for the quenching process (Figure 7). Increasing absorption coefficients and Stern-Volmer constants for the quenching by TEA resulted in enhanced performances within the first hour of irradiation (Figure 7). However, no other properties of the excited singlet state like fluorescence quantum yield or emission life time showed correlation with the performance. This indicates the importance of suitable quenching properties, as well as an efficient formation for direct sensitisation from the excited singlet state. 


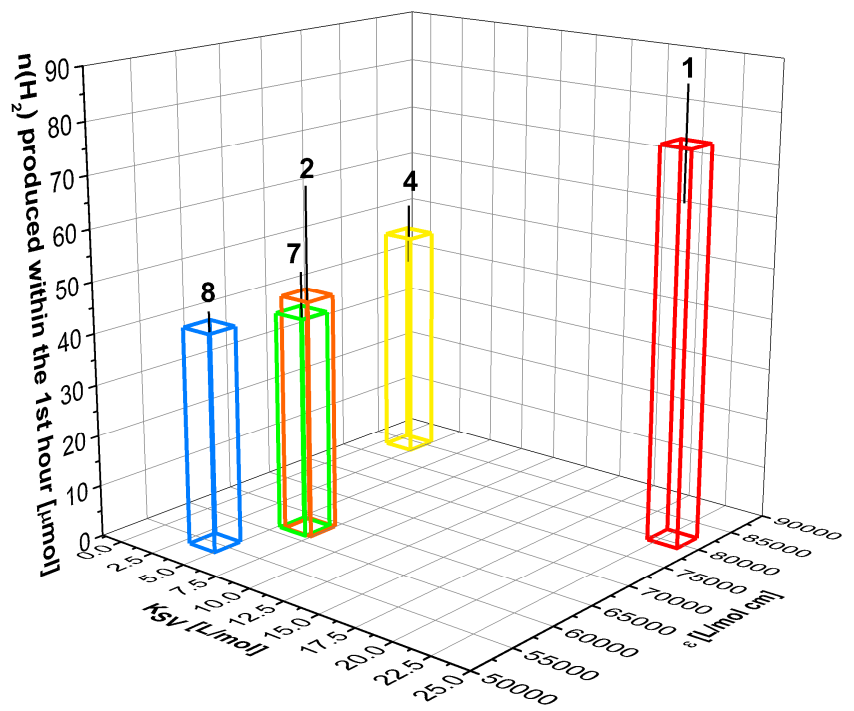

Figure 7. Effect of fluorescence quenching behaviour and absorption coefficient on the initial activity $(t=1 \mathrm{~h})$ of BODIPY dyes $1,2,4,7$, and 8 with sensitisation via the excited singlet state.

Multicomponent catalyst systems sensitised by the iodine substituted dyes showed the highest performances (1432 $\mu \mathrm{mol}$ in $250 \mathrm{~h}$ for $\mathbf{6}$ and $884 \mu \mathrm{mol}$ in $100 \mathrm{~h}$ for $\mathbf{5})$. However, 5 and $\mathbf{6}$ show weak emission quenching $\left(K_{\mathrm{SV}}<1.5\right)$ and high ISC quantum yields $\left(\Phi_{\mathrm{ISC}}=100-\Phi_{\mathrm{em}}, \Phi_{\mathrm{ISC}}>95 \%\right)$ indicating sensitisation via the triplet state in this case. Thus, the excellent performance of $\mathbf{5}$ and $\mathbf{6}$ demonstrate the superior properties of the BODIPY triplet states for photosensitisation as described previously.

\section{Materials and Methods}

\subsection{General}

The palladium source $\left[\mathrm{Pd}\left(\mathrm{PPh}_{3}\right) \mathrm{Cl}_{2}\right]_{2}$ was prepared using a described method [36]. THF was used after drying with sodium and benzophenone and distillation in an argon atmosphere unless stated otherwise. TEA was used after drying with $\mathrm{CaH}_{2}$ and distillation in argon atmosphere unless stated otherwise. All solutions and liquids in multicomponent catalyst systems were degassed via ultrasound treatment for at least 30 min before use. BODIPY dyes 1 [37], 2 [38], 3 [26], 4 [39], 5, 7, 8 [40], and 6 [41] were prepared using published procedures.

\subsection{Hydrogen Evolution Experiments}

Every multicomponent system consists of one of the photosensitisers 1-8, the palladium source $\left[\mathrm{Pd}\left(\mathrm{PPh}_{3}\right) \mathrm{Cl}_{2}\right]_{2}$, and TEA as the sacrificial agent in water or a water-containing solvent mixture. Volumetric analyses were carried out in a double-walled thermostatically-controlled reaction vessel using an automatically operating burette (MesSen Nord GmbH, Stäbelow, Germany) as described before [42]. Unless otherwise noted, volumetric curves show original data as obtained from the hydrogen evolution experiment with values being recorded automatically each $30 \mathrm{~s}$. A $300 \mathrm{~W}$ Xe arc lamp with a light output power of approximately $0.3 \mathrm{~W}$, equipped with a $420 \mathrm{~nm}$ cut-off filter and a water filter to preclude UV and IR radiation, was used as the light source. In a standard procedure, the experimental setup was evacuated and refilled with Ar three times before a $1 \mathrm{mM}$ standard solution of PS 1-8 (10 mL), a $1 \mathrm{mM}$ standard solution of $\left[\mathrm{Pd}\left(\mathrm{PPh}_{3}\right) \mathrm{Cl}_{2}\right]_{2}(1 \mathrm{~mL})$, TEA $(8 \mathrm{~mL})$ and water $(3 \mathrm{~mL})$ were transferred into the reaction vessel via syringe. Reaction solutions were degassed in an ultrasonic bath prior to use and stored under argon. To ensure isothermic measurement conditions, reaction vessel and burette were thermostated at $298.2 \pm 0.1 \mathrm{~K}$. After equilibration of the system and pressure 
compensation to atmospheric pressure, the light source was switched on. After at least 16-48 h of irradiation, the measurement was stopped and a gas sample was analysed by gas chromatography.

\subsection{Stationary Optical Spectroscopy}

Absorption spectra were measured using a Specord S 600 (Analytik Jena, Jena, Germany) spectrometer. Emission spectra were recorded from $450-700 \mathrm{~nm}$ on a Cary Eclipse (Varian, Palo Alto, CA, USA) spectrometer with excitation wavelength as denoted in the spectra with $5 \mathrm{~nm}$ slits for incident and emitted light and a detector voltage of 470-750 V depending on the dye. The samples for emission spectroscopy were prepared under exclusion of oxygen. For the Stern-Volmer experiments degassed and dried triethylamine was transferred to the cuvette via syringe under the exclusion of air. Stern-Volmer constants were determined using the numeric integral of the fluorescence signal. Absolute fluorescence quantum yields were determined directly in aerated solvents by using a PTI QuantaMaster 40 UV-VIS spectrofluorimeter (Photon Technology International, Lawrenceville, NJ, USA) equipped with an integrating sphere. Corrections for excitation and emission were applied.

\subsection{Time-Dependent Emission Spectroscopy}

Dye samples were prepared on air using THF as obtained from Roth. For quenching experiments TEA from Sigma-Aldrich (St Louis, MO, USA) was used as obtained. Spectrally-resolved emission decay curves were determined employing a Hamamatsu HPDTA streak camera (Hamamatsu, Japan). Emission is excited by pulses centered at 355 to $370 \mathrm{~nm}$ created by frequency-doubling the output of a Ti:sapphire laser (Tsunami, Newport Spectra-Physics GmbH, Stahnsdorf, Germany). The repetition rate of the fundamental is reduced to $400 \mathrm{kHz}$ by a pulse selector (Model 3980, Newport Spectra-Physics $\mathrm{GmbH})$. Emission is collected from a $1 \mathrm{~cm}$ cuvette in a $90^{\circ}$ angle and spectrally-dispersed on the detector using a CHROMEX spectrograph (Albuquerque, NM, USA). Measurements with and without a polariser (set to the magic angle) in the detection path were performed, but no contributions from rotational diffusion were observed on the time scales probed.

\section{5. ns Time-Resolved Transient Absorption Spectroscopy}

To determine excited state lifetimes of long-lived triplet states transient absorption spectroscopy with ns time-resolution was performed in setup with $90^{\circ}$ pump-probe geometry, which has been described previously [43]. The pump pulses were delivered by a Continuum OPO Plus pumped by a Continuum Surelite Nd:YAG laser (pulse duration $5 \mathrm{~ns}$, pulse-to-pulse repetition rate $10 \mathrm{~Hz}$ ), and a $75 \mathrm{~W}$ Xenon arc lamp served as source for the probe light. Spherical concave mirrors were used to focus the probe light at the sample and to refocus the light on the entrance slit of a monochromator (Acton, Princeton Instruments, Trenton, NJ, USA). The probe light was detected by a Hamamatsu R928 photomultiplier tube mounted on a five-stage base at the monochromator exit slit. The signal was processed by a commercially available detection system (Pascher Instruments AB, Lund, Sweden). By switching off the probe light emission decay can be detected by the same setup. The excitation wavelength was chosen to be centred on the strong visible absorption feature between 503 and $533 \mathrm{~nm}$, depending on the dye under investigation. The measurements were performed in a cell with $1 \mathrm{~cm}$ path length and the optical density of the sample was adjusted to be in the range of 0.3 at the excitation wavelength. The sample was prepared under the exclusion of oxygen.

\section{6. fs Time-Resolved Transient Absorption Spectroscopy}

To observe triplet state formation of the transient absorption measurements with a time resolution of $\sim 200 \mathrm{fs}$ were performed. The setup has been described in detail previously [44]. In short the output of an amplified Ti:sapphire oscillator (Libra, Coherent Inc., Santa Clara, CA, USA), producing pulses with a repetition rate of $1 \mathrm{kHz}$ centred at $800 \mathrm{~nm}(80 \mathrm{fs}, 950 \mathrm{~mJ})$, was used to pump a non-collinear optical-parametric amplifier (TOPASwhite, LightConversion Ltd., Vilnius, Lithuania) to produce pump pulses at $530 \mathrm{~nm}$. A chopper was inserted into the pump path to block every second pump pulse. 
The probe light was generated by focusing a part of the fundamental into a sapphire plate to generate a supercontinuum. The probe pulses were delayed in time with respect to the arrival of the pump pulses at the sample position by means of a delay line and split by a beamsplitter to obtain probe and reference pulses. The probe pulses were focused into the sample by means of a $200 \mathrm{~mm}$ focal-length spherical mirror. Probe-pulses were spatially and temporally overlapped at the sample position with the pump pulses, which were focused into the sample by means of a $1000 \mathrm{~mm}$ focal-length quartz lens. The polarization of the pump pulses was rotated to yield magic-angle. The probe pulse is re-collimated by a second $200 \mathrm{~mm}$ focal-length spherical mirror and in concert with the reference beam sent to the detection system, which allows for simultaneous spectrally-resolved detection of the probe and reference intensities on a double-stripe diode array. The diode array was read out with the repetition rate of the laser and the differential absorption signal was calculated from the probe and reference intensities for a pair of measurements corresponding to pump-on and pump-off conditions. The collected data was chirp corrected and fitted by a global fitting routine. The samples were prepared in a cell with $1 \mathrm{~mm}$ path length and the optical density was adjusted to 0.3 at the excitation wavelength.

\subsection{Quantum Chemical Calculations}

Quantum chemical calculations were performed for dye 2, as well as for the dyes 4-8 (Figure 1), while 2 was selected for a preliminary benchmark. Assessing excited state properties by virtue of computationally affordable time-dependent density functional theory (TDDFT) simulations is a well-known challenge for BODIPY dyes [30-33]. Therefore, following the computational protocol presented in [33], the fully-relaxed (singlet) ground state equilibrium structure of 2 was obtained using the hybrid-functional PBE0 [45-47] and the cc-pVTZ triple- $\xi$ basis set $[48,49$ ] as implemented in the Gaussian 09 program [50], while effects of interaction with the THF solvent $(\varepsilon=7.4257, n=1.4070)$ were taken into account by the integral equation formalism of the polarizable continuum model (IEFPCM) [51]. The computational setup of (TD-)PBE0/cc-pVTZ yields very good equilibrium structures and is among the best-performing (single determinate) methods to compute vertical excitation energies in extended BODIDYs [33]. A vibrational analysis showed that a minimum of the ground state potential energy (hyper) surface was obtained. Subsequently, excited state properties were calculated for the low-lying singlet and triplet excited states within the Franck-Condon region. Therefore, TDDFT (PBE0) was benchmarked against high-level multi-configurational calculations, i.e., multi-state second-order perturbation correction on a state average complete active space self-consistent field reference wavefunction (MS-CASPT2//SA-CASSCF) [23,24]. All multi-configurational calculations were performed using the Molcas 8.0 suit of programs [52] with the same basis set (cc-pVTZ) as in the geometry optimization. The Cholesky decomposition [53] was applied to generate the two-electron integrals. Single point CASSCF calculations within singlet and triplet multiplicity were performed using the state-average procedure for the seven lowest roots of the respective multiplicity on an active space (AS) $(12,11)$ comprising the entire $\pi \pi^{*}$ system of 2 and spanning over almost 61,000 configuration state functions (CSFs), see Figure S1. Dynamical correlation was included by performing (MS-)CASPT2 to improve the energies, a level shift of 0.3 a.u. was used and the core electrons were kept frozen. The oscillator strengths have been obtained at the CASSCF and MS-CASPT2 levels of theory with the CAS State Interaction method [54]. The TDDFT simulations were performed at the PBE0/cc-pVTZ level of theory for the 10 lowest energy singlet and triplet states; all TDDFT calculations were performed within solvent (THF), as well as in the gas phase.

The absorption spectra of the dyes 4-8 were exclusively obtained at the TDDFT level of theory within the fully optimised $\mathrm{S}_{0}$ equilibrium structure. All DFT and TDDFT calculations were carried out using the PBE0 XC functional and the cc-pVTZ triple- $\xi$ basis set, while the iodine atoms in dye 5 and 6 were described by means of the MWB46 [55] relativistic pseudo potential. Interactions with the THF solvent were taken into account for all ground and excited state properties by means of IEFPCM. Excited state absorption was modelled by the spin-allowed bright triplet-triplet excitation within the 
optimised $\mathrm{T}_{1}$ structure. However, no spin-orbit couplings were computed and thus, no information with respect to the accessibility of triplet states upon photoactivation can be provided. Therefore, this model is most suitable for compounds $\mathbf{5}$ and $\mathbf{6}$ featuring pronounced heavy atom effects due to the iodine atom(s). Furthermore, the equilibrium structure of the bright $S_{1}$ states of 4-8 were optimised at the TDDFT level of theory, while (TD)DFT single point calculations were carried out in the respective $\mathrm{S}_{0}, \mathrm{~S}_{1}$ and $\mathrm{T}_{1}$ equilibrium structures within singlet and triplet multiplicity.

\section{Conclusions}

A series of BODIPY dyes was used as photosensitiser components in a system containing a molecular Pd complex as the source for catalytically-active Pd nanoparticles and TEA as the sacrificial electron donor in aqueous THF solution. Photochemical and photophysical analysis confirmed that in addition to the well-known triplet state sensitisation a less common mechanism starting from the excited singlet state can be observed in BODIPY-sensitised multicomponent catalyst systems. Quantum chemical calculations have shown that the observed differences in the photophysical properties and the photochemical performance can be assigned to the efficiency of the ISC and not to variations in the characteristics of the energy levels by modification of the BODIPY substitution pattern. As a possibility for enhancing the performance of organic dyes as photosensitisers, commonly enhancement of ISC via substitution with heavy atoms for the generation of long-living excited triplet states was used. However, the importance of the generation of long-living singlet states and the improvement of quenching properties of the singlet state by a sacrificial agent or water-reduction catalyst is also evident. This design option might offer a possibility to access more stable photosensitizers as photolabile carbon-heavy atom motifs, such as C-I bonds in $\mathbf{5}$ and $\mathbf{6}$, can be avoided. An example is BODIPY dye 4 which remained stable after $20 \mathrm{~h}$ of irradiation.

Supplementary Materials: The following are available online at www.mdpi.com/2304-6740/5/2/21/s1, Volumetric data, details of the quantum chemical calculations, details of transient absorption spectroscopy.

Acknowledgments: Financial support by the Federal Ministry for Education and Research (BMBF, Project Light2Hydrogen) and the Fonds der Chemischen Industrie is gratefully acknowledged. We thank Marcus Klahn and Benjamin Andres (LIKAT) for assistance. T.B. thanks Uwe Rosenthal (LIKAT) for support. We would like to acknowledge help from Christian Reichhardt (IPHT, University Jena) with ns time-resolved experiments. All calculations were performed at the Universitätsrechenzentrum of the Friedrich-Schiller University of Jena and at the HP computers of the Theoretical Chemistry group in Jena.

Author Contributions: Torsten Beweries and Benjamin Dietzek conceived and designed the experiments; Laura Dura, Maria Wächtler, and Joachim Kübel performed the experiments; Laura Dura, Maria Wächtler, and Joachim Kübel analysed the data; Stephan Kupfer performed the quantum chemical calculations; Johannes Ahrens, Sebastian Höfler, and Martin Bröring provided BODIPY dyes; Laura Dura, Maria Wächtler, Stephan Kupfer, and Torsten Beweries wrote the paper.

Conflicts of Interest: The authors declare no conflict of interest.

\section{References}

1. Esswein, A.J.; Nocera, D.G. Hydrogen Production by Molecular Photocatalysis. Chem. Rev. 2007, 107, 4022-4047. [CrossRef] [PubMed]

2. Eckenhoff, W.T.; Eisenberg, R. Molecular systems for light driven hydrogen production. Dalton Trans. 2012, 41, 13004-13021. [CrossRef] [PubMed]

3. Fukuzumi, S.; Hong, D.; Yamada, Y. Bioinspired Photocatalytic Water Reduction and Oxidation with Earth-Abundant Metal Catalysts. J. Phys. Chem. Lett. 2013, 4, 3458-3467. [CrossRef]

4. Lakadamyali, F.; Kato, M.; Muresan, N.M.; Reisner, E. Selective Reduction of Aqueous Protons to Hydrogen with a Synthetic Cobaloxime Catalyst in the Presence of Atmospheric Oxygen. Angew. Chem. Int. Ed. 2012, 51, 9381-9384. [CrossRef] [PubMed]

5. Sakai, T.; Mersch, D.; Reisner, E. Photocatalytic Hydrogen Evolution with a Hydrogenase in a Mediator-Free System under High Levels of Oxygen. Angew. Chem. Int. Ed. 2013, 52, 12313-12316. [CrossRef] [PubMed]

6. Cheng, M.; Yang, X.; Li, J.; Zhang, F.; Sun, L. Co-sensitization of Organic Dyes for Efficient Dye-Sensitized Solar Cells. ChemSusChem 2013, 6, 70-77. [CrossRef] [PubMed] 
7. Zhang, P.; Wang, M.; Li, C.; Li, X.; Dong, J.; Sun, L. Photochemical $\mathrm{H}_{2}$ production with noble-metal-free molecular devices comprising a porphyrin photosensitizer and a cobaloxime catalyst. Chem. Commun. 2010, 46, 8806-8808. [CrossRef] [PubMed]

8. Han, Z.; McNamara, W.R.; Eum, M.-S.; Holland, P.L.; Eisenberg, R. A Nickel Thiolate Catalyst for the Long-Lived Photocatalytic Production of Hydrogen in a Noble-Metal-Free System. Angew. Chem. Int. Ed. 2012, 51, 1667-1670. [CrossRef] [PubMed]

9. Lazarides, T.; McCormick, T.M.; Du, P.; Luo, G.; Lindley, B.; Eisenberg, R. Making Hydrogen from Water Using a Homogeneous System Without Noble Metals. J. Am. Chem. Soc. 2009, 131, 9192-9194. [CrossRef] [PubMed]

10. Zhang, W.; Hong, J.; Zheng, J.; Huang, Z.; Zhou, J.; Xu, R. Nickel-Thiolate Complex Catalyst Assembled in One Step in Water for Solar $\mathrm{H}_{2}$ Production. J. Am. Chem. Soc. 2011, 133, 20680-20683. [CrossRef] [PubMed]

11. Hartley, C.L.; DiRisio, R.J.; Screen, M.E.; Mayer, K.J.; McNamara, W.R. Iron Polypyridyl Complexes for Photocatalytic Hydrogen Generation. Inorg. Chem. 2016, 55, 8865-8870. [CrossRef] [PubMed]

12. Sabatini, R.P.; McCormick, T.M.; Lazarides, T.; Wilson, K.C.; Eisenberg, R.; McCamant, D.W. Intersystem Crossing in Halogenated BODIPY Chromophores Used for Solar Hydrogen Production. J. Phys. Chem. Lett. 2011, 2, 223-227. [CrossRef]

13. Bartelmess, J.; Francis, A.J.; El Roz, K.A.; Castellano, F.N.; Weare, W.W.; Sommer, R.D. Light-Driven Hydrogen Evolution by BODIPY-Sensitized Cobaloxime Catalysts. Inorg. Chem. 2014, 53, 4527-4534. [CrossRef] [PubMed]

14. Manton, J.C.; Long, C.; Vos, J.G.; Pryce, M.T. A photo- and electrochemical investigation of BODIPY-cobaloxime complexes for hydrogen production, coupled with quantum chemical calculations. Phys. Chem. Chem. Phys. 2014, 16, 5229-5236. [CrossRef] [PubMed]

15. Luo, G.-G.; Fang, K.; Wu, J.-H.; Dai, J.-C.; Zhao, Q.-H. Noble-metal-free BODIPY-cobaloxime photocatalysts for visible-light-driven hydrogen production. Phys. Chem. Chem. Phys. 2014, 16, 23884-23894. [CrossRef] [PubMed]

16. Luo, G.-G.; Fang, K.; Wu, J.-H.; Mo, J. Photocatalytic water reduction from a noble-metal-free molecular dyad based on a thienyl-expanded BODIPY photosensitizer. Chem. Commun. 2015, 51, 12361-12364. [CrossRef] [PubMed]

17. Luo, G.-G.; Lu, H.; Zhang, X.-L.; Dai, J.-C.; Wu, J.-H.; Wu, J.-J. The relationship between the boron dipyrromethene (BODIPY) structure and the effectiveness of homogeneous and heterogeneous solar hydrogen-generating systems as well as DSSCs. Phys. Chem. Chem. Phys. 2015, 17, 9716-9729. [CrossRef] [PubMed]

18. Lazarides, T.; McCormick, T.M.; Wilson, K.C.; Lee, S.; McCamant, D.W.; Eisenberg, R. Sensitizing the Sensitizer: The Synthesis and Photophysical Study of BODIPY-Pt(II)(diimine)(dithiolate) Conjugates. J. Am. Chem. Soc. 2011, 133, 350-364. [CrossRef] [PubMed]

19. Zheng, B.; Sabatini, R.P.; Fu, W.-F.; Eum, M.-S.; Brennessel, W.W.; Wang, L.; McCamant, D.W.; Eisenberg, R. Light-driven generation of hydrogen: New chromophore dyads for increased activity based on BODIPY dye and Pt(diimine)(dithiolate) complexes. Proc. Natl. Acad. Sci. USA 2015, 112, E3987-E3996. [CrossRef] [PubMed]

20. Sabatini, R.P.; Lindley, B.; McCormick, T.M.; Lazarides, T.; Brennessel, W.W.; McCamant, D.W.; Eisenberg, R. Efficient Bimolecular Mechanism of Photochemical Hydrogen Production Using Halogenated Boron-Dipyrromethene (BODIPY) Dyes and a Bis(dimethylglyoxime) Cobalt(III) Complex. J. Phys. Chem. B 2016, 120, 527-534. [CrossRef] [PubMed]

21. Dura, L.; Ahrens, J.; Pohl, M.-M.; Höfler, S.; Bröring, M.; Beweries, T. Design of BODIPY Dyes as Photosensitisers in Multicomponent Catalyst Systems for Light-Driven Hydrogen Production. Chem. Eur. J. 2015, 21, 13549-13552. [CrossRef] [PubMed]

22. Loudet, A.; Burgess, K. BODIPY Dyes and Their Derivatives: Syntheses and Spectroscopic Properties. Chem. Rev. 2007, 107, 4891-4932. [CrossRef] [PubMed]

23. Roos, B.O. Ab Initio Methods in Quantum Chemistry II; Wiley-VCH: Chichester, UK, 1987.

24. Finley, J.; Malmqvist, P.-Å.; Roos, B.O.; Serrano-Andrés, L. The multi-state CASPT2 method. Chem. Phys. Lett. 1998, 288, 299-306. [CrossRef] 
25. Lincoln, R.; Greene, L.E.; Krumova, K.; Ding, Z.; Cosa, G. Electronic Excited State Redox Properties for BODIPY Dyes Predicted from Hammett Constants: Estimating the Driving Force of Photoinduced Electron Transfer. J. Phys. Chem. A 2014, 118, 10622-10630. [CrossRef] [PubMed]

26. Bonardi, L.; Ulrich, G.; Ziessel, R. Tailoring the Properties of Boron-Dipyrromethene Dyes with Acetylenic Functions at the 2,6,8 and 4-B Substitution Positions. Org. Lett. 2008, 10, 2183-2186. [CrossRef] [PubMed]

27. Wu, W.; Guo, H.; Wu, W.; Ji, S.; Zhao, J. Organic Triplet Sensitizer Library Derived from a Single Chromophore (BODIPY) with Long-Lived Triplet Excited State for Triplet-Triplet Annihilation Based Upconversion. J. Org. Chem. 2011, 76, 7056-7064. [CrossRef] [PubMed]

28. Kölmel, D.K.; Hörner, A.; Castaneda, J.A.; Ferencz, J.A.P.; Bihlmeier, A.; Nieger, M.; Bräse, S.; Padilha, L.A. Linear and Nonlinear Optical Spectroscopy of Fluoroalkylated BODIPY Dyes. J. Phys. Chem. C 2016, 120, 4538-4545. [CrossRef]

29. Ulrich, G.; Ziessel, R.; Harriman, A. The chemistry of fluorescent bodipy dyes: Versatility unsurpassed. Angew. Chem. Int. Ed. 2008, 120, 1184-1201. [CrossRef] [PubMed]

30. Chibani, S.; Le Guennic, B.; Charaf-Eddin, A.; Laurent, A.D.; Jacquemin, D. Revisiting the optical signatures of BODIPY with ab initio tools. Chem. Sci. 2013, 4, 1950-1963. [CrossRef]

31. Chibani, S.; Laurent, A.D.; Le Guennic, B.; Jacquemin, D. Improving the Accuracy of Excited-State Simulations of BODIPY and Aza-BODIPY Dyes with a Joint SOS-CIS(D) and TD-DFT Approach. J. Chem. Theory Comput. 2014, 10, 4574-4582. [CrossRef] [PubMed]

32. Laurent, A.D.; Adamo, C.; Jacquemin, D. Dye chemistry with time-dependent density functional theory. PhysChemChemPhys 2014, 16, 14334-14356.

33. Momeni, M.R.; Brown, A. Why Do TD-DFT Excitation Energies of BODIPY/Aza-BODIPY Families Largely Deviate from Experiment? Answers from Electron Correlated and Multireference Methods. J. Chem. Theory Comput. 2015, 11, 2619-2632. [CrossRef] [PubMed]

34. Erten-Ela, S.; Yilmaz, M.D.; Icli, B.; Dede, Y.; Icli, S.; Akkaya, E.U. A Panchromatic Boradiazaindacene (BODIPY) Sensitizer for Dye-Sensitized Solar Cells. Org. Lett. 2008, 10, 3299-3302.

35. Kolemen, S.; Cakmak, Y.; Erten-Ela, S.; Altay, Y.; Brendel, J.; Thelakkat, M.; Akkaya, E.U. Solid-State Dye-Sensitized Solar Cells Using Red and Near-IR Absorbing BODIPY Sensitizers. Org. Lett. 2010, 12, 3812-3815. [CrossRef] [PubMed]

36. Noskowska, M.; Sliwinska, E.; Duczmal, W. Simple fast preparation of neutral palladium(II) complexes with $\mathrm{SnCl}^{-}{ }_{3}$ and $\mathrm{Cl}^{-}$ligands. Trans. Met. Chem. 2003, 28, 756-759. [CrossRef]

37. Duran-Sampedro, G.; Agarrabeitia, A.R.; Garcia-Moreno, I.; Costela, A.; Bañuelos, J.; Arbeloa, T.; Arbeloa, I.L.; Chiara, J.L.; Ortiz, M.J. Chlorinated BODIPYs: Surprisingly Efficient and Highly Photostable Laser Dyes. Eur. J. Org. Chem. 2012, 6335-6350. [CrossRef]

38. Shah, M.; Thangaraj, K.; Soong, M.-L.; Wolford, L.T.; Boyer, J.H.; Politzer, I.R.; Pavlopoulos, T.G. Pyrromethene- $\mathrm{BF}_{2}$ complexes as laser dyes:1. Heteroatom Chem. 1990, 1, 389-399. [CrossRef]

39. Nepomnyashchii, A.B.; Bröring, M.; Ahrens, J.; Bard, A.J. Synthesis, Photophysical, Electrochemical, and Electrogenerated Chemiluminescence Studies. Multiple Sequential Electron Transfers in BODIPY Monomers, Dimers, Trimers, and Polymer. J. Am. Chem. Soc. 2011, 133, 8633-8645. [CrossRef] [PubMed]

40. Ahrens, J.; Haberlag, B.; Scheja, A.; Tamm, M.; Bröring, M. Conjugated BODIPY DYEmers by Metathesis Reactions. Chem. Eur. J. 2014, 20, 2901-2912. [CrossRef] [PubMed]

41. Fu, L.; Jiang, F.-L.; Fortin, D.; Harvey, P.D.; Liu, Y. A reaction-based chromogenic and fluorescent chemodosimeter for fluoride anions. Chem. Comm. 2011, 47, 5503-5505. [CrossRef] [PubMed]

42. Beweries, T.; Thomas, J.; Klahn, M.; Heller, D.; Schulz, A.; Rosenthal, U. Catalytic and Kinetic Studies of the Dehydrogenation of Dimethylamine Borane with an iPr Substituted Titanocene Catalyst. ChemCatChem 2011, 3, 1865-1868. [CrossRef]

43. Barthelmes, K.; Kübel, J.; Winter, A.; Wächtler, M.; Friebe, C.; Dietzek, B.; Schubert, U.S. New Ruthenium Bis(terpyridine) Methanofullerene and Pyrrolidinofullerene Complexes: Synthesis and Electrochemical and Photophysical Properties. Inorg. Chem. 2015, 54, 3159-3171. [CrossRef] [PubMed]

44. Siebert, R.; Akimov, D.; Schmitt, M.; Winter, A.; Schubert, U.S.; Dietzek, B.; Popp, J. Spectroscopic Investigation of the Ultrafast Photoinduced Dynamics in $\pi$-Conjugated Terpyridines. ChemPhysChem 2009, 10, 910-919. [CrossRef] [PubMed]

45. Perdew, J.P.; Burke, K.; Ernzerhof, M. Generalized Gradient Approximation Made Simple. Phys. Rev. Lett. 1996, 77, 3865-3868. [CrossRef] [PubMed] 
46. Perdew, J.P.; Burke, K.; Ernzerhof, M. Errata: Generalized Gradient Approximation Made Simple [Phys. Rev. Lett. 77, 3865 (1996)]. Phys. Rev. Lett. 1997, 78, 1396. [CrossRef]

47. Adamo, C.; Barone, V. Toward reliable density functional methods without adjustable parameters: The PBE0 model. J. Chem. Phys. 1999, 110, 6158-6170. [CrossRef]

48. Dunning, T.H. Gaussian basis sets for use in correlated molecular calculations. I. The atoms boron through neon and hydrogen. J. Chem. Phys. 1989, 90, 1007-1023. [CrossRef]

49. Woon, D.E.; Dunning, T.H. Gaussian basis sets for use in correlated molecular calculations. III. The atoms aluminum through argon. J. Chem. Phys. 1993, 98, 1358-1371. [CrossRef]

50. Frisch, M.J.; Trucks, G.W.; Schlegel, H.B.; Scuseria, G.E.; Robb, M.A.; Cheeseman, J.R.; Scalmani, G.; Barone, V.; Mennucci, B.; Petersson, G.A.; et al. Gaussian 09; Revision A.1; Gaussian, Inc.: Wallingford, CT, USA, 2009.

51. Mennucci, B.; Cappelli, C.; Guido, C.A.; Cammi, R.; Tomasi, J. Structures and Properties of Electronically Excited Chromophores in Solution from the Polarizable Continuum Model Coupled to the Time-Dependent Density Functional Theory. J. Phys. Chem. A 2009, 113, 3009-3020. [CrossRef] [PubMed]

52. Aquilante, F.; Autschbach, J.; Carlson, R.K.; Chibotaru, L.F.; Delcey, M.G.; De Vico, L.; Fdez. Galván, I.; Ferré, N.; Frutos, L.M.; Gagliardi, L.; et al. Molcas 8: New capabilities for multiconfigurational quantum chemical calculations across the periodic table. J. Comput. Chem. 2016, 37, 506-541. [CrossRef] [PubMed]

53. Aquilante, F.; Malmqvist, P.-Å.; Pedersen, T.B.; Ghosh, A.; Roos, B.O. Cholesky Decomposition-Based Multiconfiguration Second-Order Perturbation Theory (CD-CASPT2): Application to the Spin-State Energetics of Co ${ }^{\mathrm{III}}$ (diiminato)(NPh). J. Chem. Theory Comput. 2008, 4, 694-702. [CrossRef] [PubMed]

54. Malmqvist, P.-Å.; Roos, B.O. The CASSCF state interaction method. Chem. Phys. Lett. 1989, 155, $189-194$. [CrossRef]

55. Igel-Mann, G.; Stoll, H.; Preuss, H. Pseudopotentials for main group elements (IIIa through VIIa). Mol. Phys. 1988, 65, 1321-1328. [CrossRef]

(c) 2017 by the authors. Licensee MDPI, Basel, Switzerland. This article is an open access article distributed under the terms and conditions of the Creative Commons Attribution (CC BY) license (http:/ / creativecommons.org/licenses/by/4.0/). 